\title{
Implantação da disciplina Estudo de Problemas Brasileiros na UFPR (1968-1975)
}

\author{
Rudimar Gomes Bertotti \\ Rosa Lydia Teixeira Corrêa \\ Pontifícia Universidade Católica do Paraná, Brasil
}

\section{Resumo}

Neste artigo, tratamos da implantação da disciplina Estudo de Problemas Brasileiros (EPB) na Universidade Federal do Paraná (UFPR) durante a ditadura civil-militar. O objetivo deste trabalho é analisar como ocorreu sua implantação no âmbito da reforma universitária na UFPR. As fontes mobilizadas para a produção desta pesquisa foram analisadas a partir dos pressupostos teóricos da História Cultural e se concentraram em: leis, decretos, pareceres, atas e portarias publicadas pelo governo e pela UFPR durante a ditadura civil-militar. Os dados apresentados neste trabalho resultam de pesquisa desenvolvida durante o mestrado, a qual permitiu compreender a implantação da disciplina de EPB na UFPR.

Palavras-chave: Estudo de Problemas Brasileiros. Reforma Universitária. UFPR. Ditadura civil-militar. 


\section{Abstract}

In this article, we address the implementation of the discipline "Study of Brazilian Problems" (EPB) at the Federal University of Paraná (UFPR) during the civil-military dictatorship. Our aim of this work is to analyze how its implementation occurred in the scope of university reform at UFPR. The sources mobilized to produce this research were analyzed from the theoretical assumptions of Cultural History and focused on: laws, decrees, opinions and minutes published by the government and UFPR during the civil-military dictatorship. The data are the result of a research carried out during the master's degree, which allowed us to understand the implementation of the EPB discipline at UFPR.

Keywords: Study of Brazilian Problems. University Reform. UFPR. Civil-military dictatorship.

\section{Resumen}

En este artículo, abordamos la implementación de la disciplina "Estudio de problemas brasileños" (EPB) en la Universidad Federal de Paraná (UFPR) durante la dictadura civil-militar. El objetivo es analizar cómo se llevó a cabo la implementación en el ámbito de la reforma universitaria en la UFPR. Las fuentes movilizadas se analizaron a partir de los supuestos teóricos de la historia cultural y se centraron en: leyes, decretos, opiniones y actas publicadas por el gobierno y la UFPR durante la dictadura civil-militar. Los datos presentados son el resultado de una investigación llevada a cabo durante la maestría, que nos permitió comprender la implementación de la disciplina EPB en la UFPR.

Palabras clave: Estudio de problemas brasileños. Reforma Universitaria. UFPR. Dictadura civil-militar. 


\section{Resumé}

Dans cet article, nous abordons la mise en œuvre de la discipline "Éłude des problèmes brésiliens" (EPB) à l'Université fédérale de Paraná (UFPR) pendant la dictature civilo-militaire. L'objectif était d'analyser comment le processus déroulé dans le cadre de la réforme de l'université à l'UFPR. Les sources cette recherche ont été analysées à partir des postulats théoriques de l'Histoire culturelle et portaient sur: lois, décrets, avis et procès-verbaux publiés par le gouvernement et I'UFPPR pendant la dictature civilo-militaire. Les données présentées dans cette étude sont le résultat d'une recherche menée, qui nous a permis de comprendre la mise en œuvre de la discipline EPB à I'UFPR.

Mots-clés: Étude des problèmes brésiliens. Réforme de l'université. UFPR. Dictature civilo-militaire. 


\section{INTRODUÇÃO}

Ostudo de Problemas Brasileiros (EPB), componente curricular obrigatório para todos os cursos de graduação e pós-graduação do país, foi a denominação utilizada para a Educação Moral e Cívica (EMC) no ensino

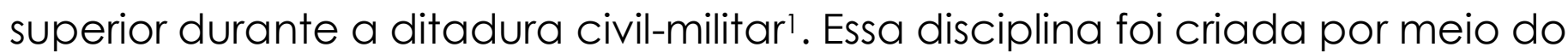
Decreto $^{2} \mathrm{~N}^{0} 869 / 69$, em um período marcado pelo protagonismo das forças armadas nos rumos da educação do país.

O texto da medida legal que criou essa disciplina fundamentou-se na proposta da Associação dos Diplomados da Escola Superior de Guerra (ADESG). O Decreto $n^{\circ}$ 869/69, que instituiu as disciplinas morais e cívicas em todos os graus e modalidades dos sistemas de ensino do país, baseou-se no anteprojeto de lei $n^{\circ} 770 / 67$, elaborado por um grupo de civis e oficiais ligados à Escola Superior de Guerra (ESG) e à ADESG, sob a coordenação do General Moacir Araújo Lopes, contendo elementos vinculados à Doutrina de Segurança Nacional e Desenvolvimento² (DSND) (Lemos, 2011).

Fundamentada sob os princípios da moral e do civismo, a EPB apresentava um perceptível conteúdo doutrinário, inclusive, no "[...] texto das Leis, [...] fica claro que a moral e cívica não era concebida primeiro como disciplina escolar, e doutrina depois; era o contrário. A moral e cívica foi uma doutrina elaborada, ao lado da Segurança Nacional" (Abreu e Inácio, 2006, p. 126).

\footnotetext{
1 Considerando a participação de civis no golpe e na manutenção do regime ditatorial, seja por adesão às ideias do governo ou pela sua efetiva participação, optou-se em utilizar o termo ditadura civil-militar no lugar da expressão ditadura militar. Essa opção não tem a intenção de desresponsabilizar ou ignorar os excessos cometidos pelos militares, mas de reconhecer a participação civil durante os 21 anos de ditadura. Existe um amplo debate historiográfico em torno das expressões que nominaram esse período. Para um aprofundamento sobre esta discussão, ver: REIS (2004); FICO (2017) e JOFFILY (2018).

2 Em linhas gerais, a DSND atribuía às Forças Armadas a missão de regeneração moral da sociedade e de combate ao inimigo interno, como forma de assegurar a Segurança Nacional.
} 
Considerando a obrigatoriedade dessa disciplina em todo território nacional, este artigo tem como objetivo analisar como ocorreu o processo de implantação desse componente sob o contexto da reforma universitária na Universidade Federal do Paraná (UFPR), bem como discorrer sobre o estabelecimento da Coordenadoria Geral de EPB, órgão responsável pela disciplina nessa instituição.

Para uma compreensão mais significativa do processo de implantação da disciplina de EPB na UFPR, objeto de estudo do presente artigo, utilizou-se como fontes: leis, decretos, pareceres, atas e portarias publicados pelo governo e pela UFPR durante a ditadura civil-militar. O recorte temporal deste estudo delimita-se entre 1968 e 1975, período que compreende a publicação do Decreto 5.540/68, que instituiu a Reforma Universitária até a regulamentação da Coordenadoria Geral de EPB na UFPR em 1975.

Os dados apresentados neste trabalho resultam de pesquisa desenvolvida durante o mestrado, no campo da História e Historiografia da Educação, o qual buscou analisar a implantação da disciplina de EPB na UFPR bem como a criação do órgão administrativo responsável pela coordenação da docência desse componente.

Para atingir o objetivo desta pesquisa, as fontes que integraram o corpus deste trabalho foram analisadas a partir dos pressupostos teóricos da História Cultural $^{3}$, com destaque para as noções de estratégia e tática de Certeau (1994), que serviram como ferramentas analíticas para compreender o

\footnotetext{
3Esta corrente historiográfica, ao privilegiar os estudos acerca da cultura bem como suas formas de representação e apropriação, ensejou a adoção de seus pressupostos no desenvolvimento do presente trabalho. Além disso, a ênfase dos estudos culturais de Certeau (1994) nas atividades de reúso ou reemprego por parte dos indivíduos frente às determinações das instituições de poder foi fundamental para a escolha da História Cultural como referencial para as análises empreendidas nesta pesquisa.
} 
processo de implantação da disciplina de EPB na UFPR durante a ditadura civil-militar.

Na acepção deste autor, a noção de estratégia é compreendida como [...] o cálculo (ou a manipulação) das relações de forças que se torna possível a partir do momento em que um sujeito de querer e poder (uma empresa, um exército, uma cidade, uma instituição científica) pode ser isolado" (1994, p. 99). A estratégia ordinariamente requer um lugar, suscetível de ser circunscrito como algo próprio e ser a base de onde se podem gerir as relações com uma exterioridade de alvos ou ameaças (Certeau, 1994).

Neste trabalho, entende-se que a UFPR caracterizou-se como um lugar de poder e ação que produzia lugares teóricos (sistemas, discursos) que se articulavam com diferentes lugares físicos (Coordenação Geral de EPB, Coordenadorias Setoriais da disciplina), nos quais as relações de força se distribuíam.

Por outro lado, na concepção de Certeau, toda estratégia produz uma tática correspondente, que o autor definiu como:

[...] a ação calculada que é determinada pela ausência de um próprio. Então nenhuma delimitação de fora the fornece a condição de autonomia. A tática não tem por lugar senão o do outro. E por isso deve jogar com o terreno que lhe é imposto tal como o organiza a lei de uma força estranha. Não tem meios para se manter em si mesma, a distância, numa posição recuada, de previsão e de convocação própria: a tática é movimento "dentro do campo de visão do inimigo", [...] e no espaço por ele controlado (1994, p. 100).

Nesse sentido, pode-se pensar na manifestação de táticas como formas de resistência frente ao estabelecimento da disciplina de EPB nos cursos de graduação e pós-graduação da UFPR.

Adotar uma perspectiva pautada nos pressupostos da História Cultural permite lançar um olhar mais significativo para a ação de diferentes agentes 
e instituições frente às determinações que a ditadura instituiu. Optar por uma abordagem que privilegia a ação dos indivíduos no tempo diverge de uma visão muito comum na historiografia tradicional sobre o período, na qual os fenômenos políticos eram apreendidos como meros reflexos das forças econômicas e sociais do momento em questão, [...] não abrindo espaço e muitas vezes desconsiderando a ação dos agentes, como se estes não tivessem participação no processo, ou ainda contemplando apenas parte deles, os militares (Gonçalves, 2012, p. 15).

\section{A Reforma Universitária Na UFPR}

Para compreender a implantação da disciplina de EPB na UFPR na década de 1970, fez-se necessário analisar o cenário de mudanças que essa instituição sofreu durante esse período. A mais relevante dessas transformações ocorreu por meio dos impactos da Lei № 5.540/68, que ficou conhecida no meio acadêmico como "Reforma Universitária".

Essa lei tinha entre suas prerrogativas uma reestruturação das universidades brasileiras capaz de satisfazer às novas solicitações do mercado de trabalho (Fávero, 2006). Em linhas gerais, essa medida legal estabeleceu o sistema departamental, o vestibular unificado, os ciclos básico e profissional, o sistema de créditos, a matrícula por disciplina, a reformulação da carreira do magistério e a pós-graduação (Baranow \& Siqueira, 2007). Além disso, a 5.540/68 prescreveu a indissociação das atividades de ensino e pesquisa e a sua concentração por áreas afins, dessa forma, disciplinas semelhantes deveriam integrar um único departamento. 
O Conselho Universitário da UFPR, com o intuito de aplicar os dispositivos da Lei 5.540/68, aprovou, no dia 2 de outubro de 1969, o novo Estatuto da UFPR homologado pelo Parecer n 197/70 do Conselho Federal de Educação (CFE) e avalizado pelo Decreto $n^{\circ}$ 66615/70, que permitiu a criação de um novo Regimento Geral da Universidade (Westphalen, 1988).

A primeira tentativa de reestruturação da Universidade com base nos dispositivos da Reforma Universitária ocorreu em 1970. Contudo, esse processo resultou na criação de quase uma centena de departamentos, onerando a instituição e não cumprindo com o princípio da concentração de disciplinas afins em um único departamento, o que resultou na rejeição da proposta pelo MEC.

Nesse contexto, uma segunda tentativa de reestruturação foi elaborada a partir do Decreto Federal $n^{\circ} 72782 / 73$. Essa nova proposta organizou a instituição em três setores básicos e cinco setores profissionais, reduzindo significativamente o número de unidades da estrutura universitária, que se restringiu a cinquenta e cinco departamentos no total (Baranow \& Siqueira, 2007). As proposições da Reforma Universitária introduziram uma série de inovações na Universidade tais como:

[...] o vestibular único e unificado, a matrícula por disciplina, a fixação de pré e co-requisitos, o sistema de créditos, o regime semestral, os currículos dos cursos de graduação, a instalação dos colegiados dos cursos, a elaboração dos catálogos dos cursos, a fixação de vagas, normas para transferências de alunos, normas para revalidação de diplomas, e certificados estrangeiros, normas para cursos de aperfeiçoamento e especialização, a estruturação do ciclo básico por áreas, etc (Westphalen, 1987, p. 106).

Essa reorganização da Universidade também foi integrada por nove órgãos suplementares: Biblioteca Central, Hospital das Clínicas, Imprensa Universitária, Centro de Computação Eletrônica, Centro de Estações 
Experimentais, Museu de Arqueologia e Artes Populares, Centro de Educação Física e Desportos, Centro de Recursos Audiovisuais, Orquestra e Coral Universitário.

O Estatuto de 1974 de maneira semelhante contemplou os cursos de pósgraduação, cujo objetivo seria o de desenvolver e aprofundar a formação obtida nos cursos de graduação. Esse documento previa cursos em nível de mestrado e doutorado, além de cursos de aperfeiçoamento e especialização.

O Regimento Geral da UFPR de 20 de dezembro de 1974 previa a entrega de um projeto ao Conselho de Ensino e Pesquisa, com antecedência de 90 dias, como pré-requisito para a criação de um curso de pós-graduação. Para a obtenção do grau de mestre eram necessárias a aprovação nas disciplinas do plano curricular e a apresentação da dissertação (que revelasse domínio do tema, capacidade de sistematização e pesquisa bibliográfica), aprovação da dissertação por três especialistas e prova de capacidade de tradução de um texto em língua estrangeira. Para a obtenção do grau de doutor eram necessárias a aprovação nas disciplinas, a apresentação de tese (que constituísse contribuição significativa para o conhecimento do tema), a aprovação em defesa de tese por cinco especialistas e prova de capacidade de tradução de textos em duas línguas estrangeiras (Siqueira \& Trindade, 1998, p. 94).

A Reforma Universitária empreendida entre 1970 e 1974 alterou de forma significativa a estrutura da universidade. A adoção de medidas, como a extinção de órgãos, criação de novos cursos, reorganização de departamentos e setores, criação de novas disciplinas e reestruturação da hierarquia administrativa, propiciaram um cenário de mudanças que permeou todo processo de implantação da disciplina de EPB na UFPR.

\section{O processo de implantação da disciplina Estudo de problemas brasileiros na UFPR}


O processo de implantação da disciplina de EPB na UFPR ocorreu no ano de 1971, cerca de um ano e meio após a publicação do Decreto n 869/69 que instituiu a obrigatoriedade da EPB em todos os cursos de graduação e pósgraduação do país.

Para alcançar os objetivos definidos na parte introdutória deste artigo, este estudo debruçou-se na análise das atas do Conselho Universitário da UFPR, depreendendo dessas fontes fragmentos sobre a discussão acerca do processo de implantação da EPB ocorrida no dia 27 de maio de 1971.

De acordo com o parecer oral do relator e Conselheiro, José Nicolau dos Santos, a implantação da disciplina de EPB foi amplamente discutida pelo Conselho Universitário da UFPR, que decidiu aprovar a designação de até catorze professores para lecionarem a EPB na universidade (UFPR, 1971). Os fragmentos da ata também apontaram que a remuneração desses docentes seria realizada por meio de uma gratificação correspondente a $100 \%$ do vencimento básico. Além disso, o Conselho igualmente aprovou a contratação de conferencistas estranhos à universidade, caso a matéria exigisse um especialista. Segundo as discussões do Conselho Universitário, a aula inaugural da EPB seria proferida na Faculdade de Odontologia sob o título "Principais Problemas Brasileiros".

Seguindo as prescrições do Parecer n 94/71, o Conselho Universitário sugeriu a criação de uma Coordenação Geral responsável pela EPB, cuja função seria a de orientar a docência deste componente nos cursos da UFPR. Em um primeiro momento, esse órgão deveria ser presidido pelo Conselheiro Brasil Pinheiro Machado e composto por professores designados (UFPR, 1971). A princípio, os docentes de EPB deveriam ser indicados pelos diretores dos departamentos dos cursos, o Conselho também decidiu que a Faculdade de 
Educação organizaria uma formação para os futuros professores da disciplina de EPB (UFPR, 1971).

Considerando que o Decreto $n^{\circ} 869 / 69$, que instituiu a obrigatoriedade da EPB nas instituições de ensino superior, não contemplou, no texto da lei, orientações sobre os conteúdos a serem ministrados nas aulas de EPB, não houve, de fato, um detalhamento das diretrizes a serem seguidas, ou seja, ele acabou por gerar empecilhos para a introdução da EPB nas instituições de ensino superior do país. Entretanto, a Comissão Nacional de Moral e Civismo (CNMC), a partir de um ofício encaminhado para apreciação do CFE no dia 28 de janeiro de 1970, permitiu a possibilidade de implantar a EPB ainda no ano letivo de 1970, a partir das orientações do documento "Subsídios para Currículos e Programas Básicos de Educação Moral e Cívica".

Contudo quem tinha a incumbência de definir o programa de ensino, bem como os conteúdos de EPB, era o CFE e não a CNMC. Sendo assim, o CFE publicou o Parecer n 101/70 afirmando que o órgão não dispunha de tempo para discutir de forma aprofundada sobre a questão, sugerindo por meio do documento a criação de uma Comissão integrada por membros das Câmaras de Ensino Superior e de Ensino Primário e Médio para estabelecer os programas de ensino e os conteúdos das disciplinas morais e cívicas nos diferentes níveis de escolarização. Essa Comissão definiu na Indicação nº 8, de 26 de junho de 1970, que as instituições de ensino4, a partir do segundo semestre letivo daquele ano, incluíssem o ensino das disciplinas morais e cívicas em suas estruturas curriculares (Lemos, 2011).

\footnotetext{
4 Instituições de ensino como a UFR conseguiram implantar a EPB ainda no ano letivo de 1970, orientando o processo de implementação da disciplina naquela universidade por meio de um plano de emergência publicado pelo CFE na Indicação nº 8/70.
}

11 Linhas Críticas, Brasília, DF, v. 25 - Ahead of print, p. 1-28. 
Tendo em vista que o reitor da UFPR era então o professor Flávio Suplicy Lacerda, educador alinhado aos ideais do regime e ex-ministro da educação de Castelo Branco, e que a definição acerca da implementação da disciplina pelo CFE ocorreu somente no segundo semestre de 1970, compreende-se que a EPB foi ofertada na Universidade dentro do prazo estipulado por lei.

No ano seguinte, na implantação da disciplina, o professor Maury Rodrigues da Cruz assumiu o cargo de Coordenador Geral da EPB na UFPR. Esse docente já fazia parte do quadro da Universidade, lecionando as disciplinas de Legislação Social e Ciência Política desde a década de 1960. Como evidência da sua admissão ao cargo, foi encontrado um programa de ensino assinado por esse docente em março de 1972.

Por outro lado, após análise do boletim administrativo da UFPR $n^{\circ} 218$ de julho de 1973, constatou-se por meio da Portaria $n^{\circ} 10.078$, que uma comissão formada pelos professores Ocyron Cunha, Ernani Simas Alves e Newton França Bittencourt Filho incumbiu-se de apresentar um projeto que centralizasse a organização do ensino de EPB em único órgão (UFPR, 1973a). Dois meses depois, a UFPR sancionou a Portaria $n^{\circ} 10.398$, prescrevendo orientações sobre a seleção de docentes para o ensino de EPB. O conteúdo dessa Portaria estabeleceu que quando o Diretor do Departamento não fosse o responsável pela docência da EPB, a Reitoria nomearia um Coordenador setorial para a docência deste componente (UFPR, 1973b).

O conteúdo dessas portarias denota esforços para estruturar o ensino da EPB na Universidade que, em tese, apresentava-se sob a alçada da Coordenadoria Geral de EPB, órgão responsável pela produção dos programas de ensino da disciplina desde 1972. Contudo, conforme as prescrições da Portaria $n^{\circ} 10.398$, a UFPR, a partir de 1973, delegou para os 
departamentos a responsabilidade pelo ensino da EPB. Esse processo de descentralização da responsabilidade pela docência da disciplina culminou na extinção da Coordenadoria Geral de EPB no ano seguinte, transferindo aos setores as atribuições da Coordenação Geral de EPB. Segundo a Portaria $n^{\circ} 11.306$, publicada no dia 8 de fevereiro de 1974:

O Diretor de cada Unidade, nos termos do disposto no artigo $7^{\circ}, \S 6^{\circ}$, do Decreto Lei n. 869, de 12 de setembro de 1969, será o responsável pelo ensino de Estudo de Problemas Brasileiros, podendo delegar poderes a um Docente da UFPR, o qual será Coordenador Setorial da disciplina (UFPR, 1974a).

Entretanto, durante o levantamento das fontes nos acervos da UFPR, foi encontrado um programa de ensino de 1974 com a assinatura do Coordenador Geral de EPB, professor Maury Rodrigues da Cruz, bem como o carimbo do órgão no documento. Diante dessas evidências, conjecturou-se que os primeiros anos da implantação da EPB passaram por duas fases distintas. Na primeira, pressupõe-se que a Coordenação Geral foi responsável pela elaboração de um programa de ensino bem como pela seleção e organização do corpo docente da EPB nos cursos no ano de 1972. Mas que a partir de 1973, a responsabilidade pela organização do ensino da EPB foi transferida para os departamentos, ficando a cargo da Coordenação Geral de EPB apenas a produção e difusão dos programas de ensino da disciplina. A Portaria $n^{\circ} 11.306$ também estabelecia uma série de orientações sobre a disposição da EPB na UFPR:

A disciplina de EPB deverá ser ministrada:

a) em 2 (dois) períodos letivos (EPB - 1 e EPB - 2);

b) com a carga horária mínima de 2 (duas) horas aula semanais, correspondendo a 2 (dois) créditos por período letivo;

c) sempre que possível, nos mesmos turnos que as de Educação Física. A disciplina de EPB será preferencialmente oferecida aos alunos nos 4 (quatro) últimos períodos letivos de cada curso. Nos cursos em regime 
Além das prescrições que tratavam sobre a organização do ensino da EPB na Universidade, a Portaria UFPR nº 11.306 também demonstrou o controle que existia sobre essa disciplina na instituição. Segundo essa medida legal, no início de cada mês, o Diretor de cada setor deveria encaminhar à AESI (Assessoria Especial de Segurança e Informações) o conteúdo ministrado nas aulas do mês anterior.

\begin{abstract}
Até o dia 10 do mês subsequente, o Coordenador Setorial de EPB, por intermédio do Diretor do Setor, enviará à AESI um relatório sucinto das atividades mensais executadas, acompanhado dos planos de aula e dos textos distribuídos aos alunos (UFPR, 1974a).
\end{abstract}

A partir dessas prescrições, reitera-se o aspecto descentralizador que essa medida legal incutiu na organização do ensino de EPB na UFPR, destacando que enquanto não fossem estabelecidos critérios uniformes para todos os cursos da Universidade, os Diretores dos Setores deveriam controlar a frequência dos alunos e administrar o ensino da disciplina no Setor. Além disso, a redação dessa medida orientava que até os dias 28 de fevereiro e 31 de julho de cada ano, os diretores deveriam encaminhar à Reitoria, para aprovação, o plano de curso da disciplina de EPB a ser desenvolvido em cada semestre letivo (UFPR, 1974a).

Pelo conteúdo das fontes analisadas neste estudo, depreende-se que os primeiros anos de implantação da disciplina de EPB foram marcados por indefinições no que tange à organização da docência deste componente. Indefinições circunscritas até o dia 7 de agosto de 1975, data em que foi publicada a Portaria UFPR n. 13.711, que reinstituiu a Coordenadoria Geral de EPB e o cargo de Coordenador Geral como responsável pela oferta e gestão da disciplina na Universidade. 


\section{A coordenação geral da disciplina Estudo de problemas brasileiros na UFPR}

O Parecer $n^{\circ}$ 94, de 13 de fevereiro de 1971, publicado pelo CFE, prescrevia a criação de um órgão para coordenar a disciplina de EPB, bem como um coordenador para administrar seu ensino. Essa medida legal reiterou que, para a docência da EPB, não deveria haver um professor, mas um coordenador, sob a alegação de que a amplitude da disciplina exigia professores de distintas áreas do conhecimento, no sentido de apontar os problemas e as soluções que afligiam a população brasileira nos anos 1970.

O Parecer estabelecia que o coordenador teria autonomia para promover painéis e debates na universidade. De acordo com essa medida legal:

À imaginação e ao espírito de empreendimento de cada Coordenador incumbirá a tarefa de fazer da aula de Estudos Brasileiros não uma disciplina obrigatória (no sentido pejorativo), mas uma encruzilhada viva de questões e ideias, em que a Realidade do Brasil, o esforço do Desenvolvimento Nacional e os ideais da Democracia no Brasil entram como componentes portadores de alta carga de interesse patriótico e de dinamismo construtivo (BRASIL, 1971lb).

Também há menção sobre as atribuições desse órgão no Regimento Geral da UFPR, aprovado no dia 27 de dezembro de 1974, que em seu artigo 256 mencionava que a Coordenação Geral de EPB promoveria "[...] seminários, debates e estudos sobre a problemática nacional, regional e local, especializando equipes para ministrar a disciplina" (UFPR, 1974C). De acordo com o Regimento, as atividades e o funcionamento desse órgão seriam definidos pela Reitoria.

Conforme visto anteriormente, a Coordenação Geral de EPB só adquiriu respaldo legal da Reitoria por meio da Portaria $n^{\circ} 13.711$, em agosto de 1975. 
Contudo, os programas de ensino de EPB de 1972, 1973 e 1974, asseguram a existência desse órgão, que aparentemente subsistiu informalmente, sendo o responsável pela elaboração dos programas e dos conteúdos a serem ministrados nas aulas de EPB, mas sem a competência de selecionar e administrar o corpo docente encarregado de ministrar as aulas deste componente nos diferentes setores da Universidade.

Ao problematizar as razões que exigiram quatro anos para respaldar legalmente um espaço institucional para a organização do ensino da EPB na UFPR, cogitaram-se duas hipóteses.

Primeiramente, a utilização de condutas táticas por parte dos envolvidos na organização da disciplina na universidade, o que, possivelmente, teria impossibilitado a implantação de uma coordenação respaldada legalmente no âmbito da UFPR antes de agosto de 1975. Sob a perspectiva certeauniana, as táticas correspondem às ações que se opõem às estratégias. Podem ser definidas como formas de resistência que não pretendem qualquer posição de poder, mas que se aproveitam das [...] "ocasiões" e delas depende, sem base para estocar benefícios, aumentar a propriedade e prever saídas. O que ela ganha não se conserva (Certeau, 1994, p. 100).

Em segundo lugar, a consideração do contexto vivido na UFPR, devido aos desdobramentos da reforma universitária que só chegaria ao fim com a publicação de um estatuto em 1974, o que implicaria uma demora no processo de criação de uma coordenação geral, levando à implementação somente no segundo semestre de 1975.

A medida legal responsável pela criação oficial da Coordenação Geral de EPB também tratou de inúmeras questões relevantes para a organização e o 
funcionamento da disciplina. No trecho introdutório da Portaria $n^{\circ} 13.711$, o Reitor teceu as seguintes considerações sobre a disciplina:

O Reitor da Universidade Federal do Paraná, no uso de suas atribuições, e-Considerando as determinações do Decreto-lei 869, de 12 de setembro de 1969, - Considerando os dispositivos do Decreto $\mathrm{n}$. 68065, de 14 de janeiro de 1971, - Considerando as implicações do Parecer n. 94, de 04 de fevereiro de 1971 do Conselho Federal de Educação, - Considerando a necessidade de implantação de uma doutrina compatibilizada com os objetivos do ensino da matéria "Estudo de Problema Brasileiros", - Considerando a urgência em fixar uma política de ensino numa linha de integração com a formação de profissionais de nível superior da Universidade Federal do Paraná, Considerando, ainda, a inexistência de diretrizes na formação do quadro de professores para atuar na matéria "Estudo de Problemas Brasileiros" (UFPR, 1975).

Ainda de acordo com essa Portaria:

Art. $1^{\circ}$ - fica criada a Coordenação de Estudos Brasileiros na Universidade Federal do Paraná (Art. 256 do Regimento Interno) subordinada à Reitoria, com a finalidade de dirigir, orientar, controlar e promover o ensino da disciplina Estudo de Problemas Brasileiros, além de propiciar oportunidade para debates, seminários e pesquisas sobre a problemática Nacional, Regional e Local.

$\S 1^{\circ}$ - A coordenação de EPB será exercida por um Coordenador de livre escolha e designação do Reitor;

$\S 2^{\circ}$ - O coordenador exercerá o cargo, preferentemente, em regime de tempo integral com ou sem dedicação exclusiva;

$\S 3^{\circ}$ - O Vice-Coordenador substituirá o Coordenador nos seus impedimentos, e será igualmente designado pelo Reitor;

$\S 4^{\circ}$ - É vedada a acumulação das funções de Coordenador com quaisquer outras de direção ou representação (UFPR, 1975).

Para administrar o ensino da EPB na Universidade, a Coordenação Geral de EPB ocupou uma sala no subsolo do prédio histórico da UFPR localizado na Praça Santos Andrade. Neste espaço, o Coordenador Geral da disciplina, professor Maury Rodrigues da Cruz, agora respaldado legalmente como gestor do ensino da EPB na Universidade, planejava e orientava a docência dessa disciplina na UFPR. 
Além do espaço físico destinado à Coordenação Geral de EPB, a Portaria UFPR $n^{\circ} 13.711$ prescrevia no seu artigo $3^{\circ}$ a instalação dos [...] "Centros Superiores de Civismo, estabelecendo contatos com todos os Órgãos da Universidade, a fim de indicar suas respectivas sedes e dar apoio de recursos humanos" (UFPR, 1975). Entretanto, esses Centros não chegaram a existir na Universidade.

O artigo seguinte da Portaria UFPR $n^{\circ} 13.711$ tratava da seleção dos profissionais responsáveis pela docência da EPB na Universidade, agora sob incumbência da Coordenação Geral de EPB e não mais pelos departamentos da UFPR. Segundo essa medida legal:

Art. $4^{\circ}$ - A admissão de professores ou aproveitamento de docentes de outras áreas para exercerem atividade didática na disciplina de EPB deverá receber parecer da Coordenação de EPB, que orientará o seu processo (UFPR, 1975)

O artigo $4^{\circ}$ também prescrevia que após a seleção empreendida pela Coordenação, os processos seletivos deveriam ser encaminhados para a AESI para sua avaliação.

As atribuições do Coordenador Geral da EPB também foram delineadas na Portaria UFPR $n^{\circ} 13.711$ e previam desde a fixação de diretrizes básicas para a docência da EPB até a aplicação de penas disciplinares nos casos previstos em lei. De acordo com o artigo $6^{\circ}$ :

[...] Compete ao Coordenador de EPB: I) exercer a coordenação do ensino de EPB na UFPR, fixar as diretrizes básicas do programa didático, visando sua integração nos Cursos; II) orientar e fiscalizar as atividades didáticas das disciplinas de EPB; III) estabelecer normas ao desempenho dos professores e orientadores a serem designados; IV) promover seminários, debates e estudos sobre a problemática Nacional, Regional e Local, especializando equipes para ministrar a matéria; V) planejar e organizar juntamente com as Coordenações Setoriais de EPB, a previsão de ofertas, estabelecendo colaboração com os Departamentos de Ensino da UFPR; VI) instaurar procedimento e propor aplicação de pena disciplinar nos casos previstos em lei; VII) 
exercer outras atribuições previstas em lei, regulamento ou regimento (UFPR, 1975).

O trecho final desta Portaria prescrevia que a recém-criada Coordenação deveria, no máximo em três meses da publicação desta medida, encaminhar para a Reitoria um Regimento para a disciplina de EPB e um Plano de Trabalho para o $1^{\circ}$ semestre de 1976.

Apesar dessa normativa, só foi encontrado nos arquivos da Universidade o Plano de Trabalho do $2^{\circ}$ semestre de 1976, que embora não fosse 0 documento buscado nos acervos, permitiu observar as novas orientações acerca da organização e do ensino desse componente curricular na Universidade. 


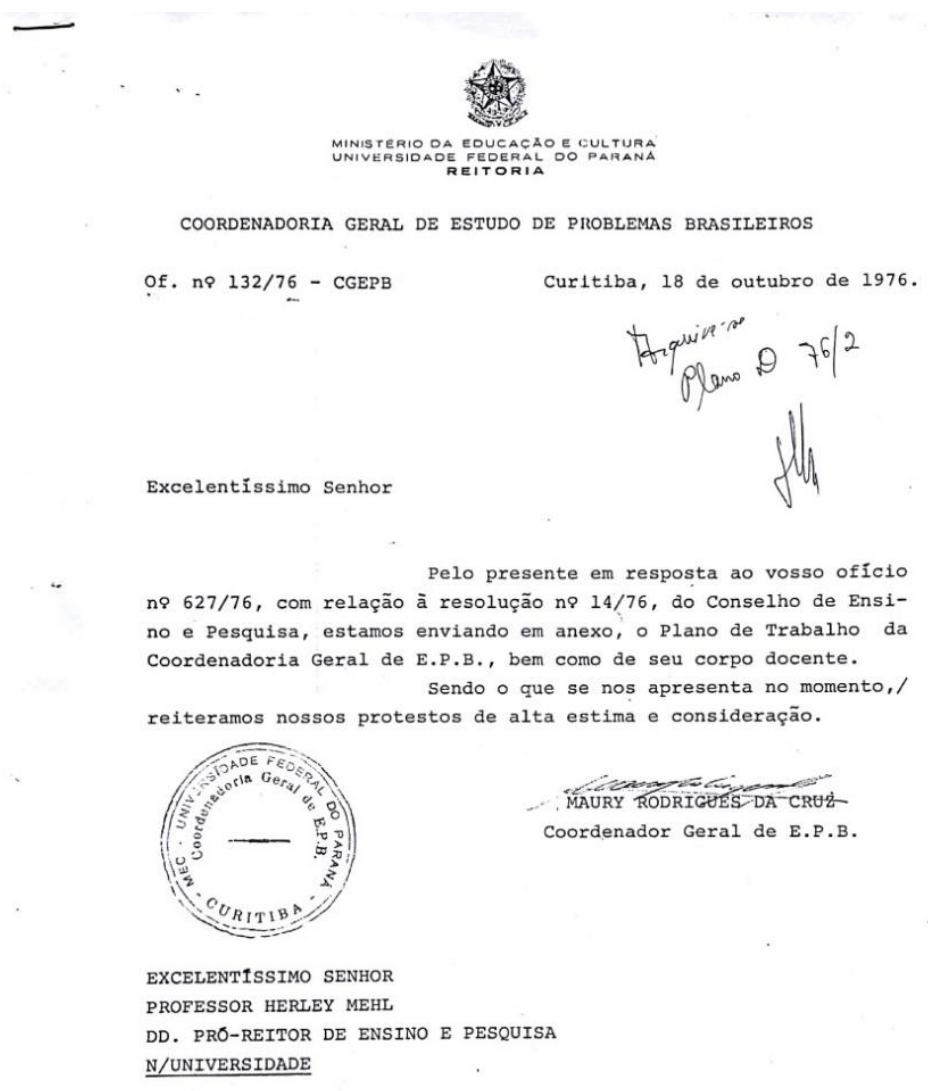

O plano de trabalho, elaborado pela coordenação geral de EPB para o segundo semestre de 1976, discriminava atividades docentes relativas aos cursos de graduação e pós-graduação. Eram ofertadas 84 horas-aula semanais nos cursos de graduação da UFPR, aulas essas divididas entre 21 professores que compunham o corpo docente da disciplina.

Colaboradores $^{5}$ setoriais também auxiliaram a coordenadoria geral na organização e promoção do ensino de EPB nos diversos departamentos da

\footnotetext{
5 Os Coordenadores setoriais de EPB na UFPR eram docentes da disciplina que auxiliavam a Coordenação Geral na organização e promoção do ensino deste componente curricular na universidade. É importante ressaltar que essa função não chancelava o exercício de censor a esses indivíduos (BERTOTTI, 2015).
} 
universidade. Segundo um documento desprovido de data, obtido nos arquivos da UFPR, esse grupo foi compostos pelos seguintes professores:

Quadro 1 - relação dos coordenadores setoriais da disciplina de EPB. fonte: UFPR $(s \backslash d)$.

\begin{tabular}{|l|l|}
\hline Coordenadores setoriais da disciplina de EPB da UFPR \\
\hline Setor de ciências sociais aplicadas & Enio José Coimbra de Carvalho \\
\hline $\begin{array}{l}\text { Setor de ciências humanas, letras e } \\
\text { artes }\end{array}$ & $\begin{array}{l}\text { Maria de Lourdes Montenegro } \\
\text { Holzmann }\end{array}$ \\
\hline Setor de educação & Maria Olga Mattar \\
\hline Setor de ciências da saúde & Ernani Simas Alves \\
\hline Setor de ciências agrárias & Humberto Carlos Falce \\
\hline Setor de ciências exatas & Manoel Oliveira Teixeira \\
\hline Setor de ciências biológicas & ---------------- \\
\hline Setor de tecnologia & Alceu Rolkoski \\
\hline
\end{tabular}

No tocante às aulas da pós-graduação, um total de 90 horas-aula estava disponível para a coordenação geral de EPB no $2^{\circ}$ semestre de 1976.

O plano de trabalho também discorria sobre as incumbências administrativas do coordenador geral da EPB e do da disciplina. Segundo esse documento, as atividades coordenativas se traduziam em:

-Exercício e coordenação do ensino de EPB na UFPR, fixando as diretrizes básicas do programa didático.

-Orientação e fiscalização das atividades didáticas das disciplinas de EPB.

-Estabelecimento de normas ao desempenho dos professores e orientadores a serem designados.

-Promoção de seminários, palestras, conferencias, etc.

-Planejamento e organização da previsão de ofertas.

-Instauração de procedimento, aplicação de pena, etc.

Exercício de outras atribuições previstas em lei, regulamento ou regimento, de acordo com a Portaria n. 13.711, de 07 de outubro de 1975 que criou a Coordenadoria Geral de EPB (UFPR, 1976). 
A análise das fontes que documentam o processo da implantação da disciplina de EPB na UFPR denota que esse processo foi marcado por algumas adversidades. Dentre elas, a alternância de coordenadores gerais nos três primeiros anos da disciplina e, inclusive, a ausência dessa figura em 1974, o que denota um processo de apropriação particular da legislação que determinava a obrigatoriedade dessa disciplina na UFPR.

Apesar desses problemas no tocante à coordenação da disciplina durante seu processo de implantação, a estratégia de introdução de um componente curricular pautado nos princípios da moral e do civismo e interpelado pela DSND efetivou-se, pois a estrutura dos programas de ensino e, consequentemente, o cumprimento das orientações do Parecer CFE n. 94/7171, permaneceu a mesma até 1984, momento em que o professor Maury Rodrigues da Cruz deixa a coordenação da disciplina, conforme atesta o quadro 2. 
Quadro 2 - tabela comparativa' ${ }^{6}$ do programa de ensino publicado pelo parecer $n$. 94/71 e o programa de ensino utilizado na UFPR em 1983 - Fonte: parecer cfe n. 94/71 e programa de ensino de EPB da UFPR 1983.

\begin{tabular}{|l|l|}
\hline Programa do Parecer No 94/71 & Programa de Ensino UFPR 1983 \\
\hline $\begin{array}{l}\text { Unidade I } \\
\text { Panorama Geral da Realidade } \\
\text { Brasileira }\end{array}$ & $\begin{array}{l}\text { UNIDADE I } \\
\text { Panorama Geral da Realidade } \\
\text { Brasileira }\end{array}$ \\
\hline UNIDADE II & UNIDADE II \\
Problemas Morfológicos & Problemas Morfológicos \\
\hline UNIDADE III Problemas de & UNIDADE III Problemas de \\
Desenvolvimento Econômico & Desenvolvimento Econômico \\
\hline UNIDADE IV & UNIDADE IV \\
Problemas Sócio-Econômicos & Problemas Sócio-Econômicos \\
\hline UNIDADE V & UNIDADE V \\
Problemas Políticos & Problemas Políticos \\
\hline UNIDADE VI & UNIDADE VI \\
Segurança Nacional & Segurança Nacional \\
\hline
\end{tabular}

Além disso, a permanência desse professor como Coordenador Geral de EPB por mais de dez anos ratifica a concretização dessa estratégia, pois ele era um profundo defensor das potencialidades que a disciplina de EPB poderia oferecer ao aprimoramento do caráter dos jovens que ingressavam na Universidade.

Por outro lado, a retomada da democracia em 1985 e a perda de legitimidade da disciplina, em alguns casos, transformaram as aulas de EPB em espaços para a discussão e o ensino de outros componentes curriculares que não constavam no programa de ensino da EPB (BERTOTTI, 2015).

\footnotetext{
6 Os programas de ensino organizados pela Coordenação Geral de EPB na UFPR durante a ditadura civil-militar seguiram fielmente às prescrições do Parecer CFE n. 94/71, sendo reproduzidos até 1984 de forma absolutamente idêntica ao programa anexo ao Parecer n. 94/71 do CFE.
} 


\section{Considerações Finais}

Analisar o processo de implantação da disciplina de EPB na UFPR, sob o contexto da reforma universitária, ajudou a perceber a centralidade que o ensino superior ocupou nas reformas educacionais promovidas durante a ditadura civil-militar. A introdução de uma disciplina moral e cívica, obrigatória para todos os cursos de graduação e pós-graduação do país, denota a importância que a ditadura conferiu ao ensino da EPB nas instituições de ensino superior do Brasil.

Este estudo permitiu compreender as transformações que a UFPR experimentou durante $\mathrm{o}$ processo de reestruturação administrativa provocada pelos dispositivos da legislação da Reforma Universitária. Mudanças como a extinção de órgãos, criação de novos cursos, reorganização de departamentos e setores, criação de novas disciplinas e reestruturação da hierarquia administrativa permearam a implantação da disciplina de EPB nas matrizes curriculares de todos os cursos graduação e pós-graduação da universidade.

Compreender o processo que culminou na implantação da disciplina de EPB na UFPR, a partir do mês de maio de 1971, permitiu explorar de forma mais significativa como os sujeitos responsáveis por cumprir as determinações do Decreto n 869/69 operaram na implementação da EPB na universidade. Nesse sentido, as atas do conselho universitário se mostraram fundamentais, pois permitiram a apreensão de evidências sobre esse importante processo. Além das atas do conselho universitário, os boletins administrativos da universidade foram imprescindíveis para a compreensão da organização do ensino da EPB após sua implantação. 
As portarias publicadas pela universidade em seus boletins administrativos possibilitaram a apreensão de um processo de descentralização gradativo da organização da disciplina até uma abrupta centralização sob a égide da Coordenação Geral de EPB em 1975, ano em que uma portaria da UFPR respaldou legalmente esse órgão administrativo.

Outro aspecto que chamou a atenção durante a produção deste trabalho foi o controle que a AESI exerceu sobre a contratação do corpo docente responsável pelo ensino da EPB, bem como pelos conteúdos ministrados durante as aulas dessa disciplina.

Por fim, o estabelecimento de uma Coordenação Geral para uma disciplina pautada nos princípios da moral e do civismo, bem como o êxito de implantação deste componente curricular em todos os cursos da universidade, ratifica a projeção que a DSND obteve no cenário educacional por meio do ensino da EPB durante a ditadura civil-militar.

Data da submissão: 19/02/2019

Data do aceite: 19/01/2020 


\section{REFERÊNCIAS}

Abreu, Vanessa Kern de. \& Inácio, G., Filho. (2006). A Educação Moral e Cívica - doutrina, disciplina e prática educativa. Revista Histedbr, Campinas, n.24, p. $125-134$.

Baranow, Ulf G. \& Siqueira, Márcia Dalledone. (2007). Universidade Federal do Paraná: história e estórias (1912-2007). Curitiba: Editora da UFPR,.

Certeau, Michel. (1994). A invenção do cotidiano. Vol. 1: Artes de fazer. 4. ed. Petrópolis, RJ: Vozes.

Fávero, Maria de Lourdes de Albuquerque. (2006). Universidade do Brasil: das origens à Reforma Universitária de 1968. Educar em Revista, Curitiba, n. 28, p. 17-36.

Gonçalves, Nadia Gaiofatto. A Escola Superior de Guerra e a Lei 5692/71: Discursos Governamentais e Implementação da Lei no Paraná. In: Gonçalves, Nadia Gaiofatto e Ranzi, Serlei Maria Fischer. (orgs.) Educação na ditadura civil-militar: politicas, ideários e práticas (Paraná, 1964-1985). Curitiba: Editora da UFPR, 2012.

Lemos, Kaé Stoll Colvero. (2011). A normatização da Educação Moral e Cívica (1961-1993). Mestrado em Educação. Universidade Federal do Rio de Janeiro: Rio de Janeiro.

Siqueira, Márcia Dalledone. (Org.); Trindade, Etelvina. (1998). Rumos da Pesquisa: uma história da pesquisa e Pós-graduação na UFPR. Curitiba: UFPR.

Universidade Federal do Paraná (1972). Programa de ensino da disciplina Estudo de Problemas Brasileiros. Curitiba.

Universidade Federal do Paraná (1971). Conselho Universitário. Ata da reunião realizada no dia 27 de maio. Livro 4, p. 30.

Universidade Federal do Paraná (1973a). Portaria n 10.078, de 29 de junho. Universidade Federal do Paraná (1973b). Portaria $n^{\circ} 10.398$, de 6 de setembro. Universidade Federal do Paraná (1973c). Portaria $n^{\circ} 10.425$, de 13 de setembro.

Universidade Federal do Paraná (1973d). Programa de ensino da disciplina Estudo de Problemas Brasileiros. Curitiba.

Universidade Federal do Paraná (1974a). Portaria n 11.306, de 8 de fevereiro. Universidade Federal do Paraná (1974b). Programa de ensino da disciplina Estudo de Problemas Brasileiros. Curitiba.

Universidade Federal do Paraná (1974c). Regimento Geral da Universidade Federal do Paraná, de 20 de dezembro.

Universidade Federal do Paraná (1975). Portaria n 13.711, de 7 de agosto. 
Universidade Federal do Paraná (1976). Plano de Trabalho Departamental da disciplina Estudo de Problemas Brasileiros. Curitiba.

Universidade Federal do Paraná. Relação dos Coordenadores Setoriais da disciplina de EPB I. Curitiba, s/d.

Westphalen, Cecília Maria. (1987). Universidade Federal do Paraná: 75 anos. Curitiba: SBPH-PR.

Westphalen, Cecília Maria. (1988) Faculdade de Filosofia, Ciências e Letras do Paraná: 50 anos. Curitiba: SBPH-PR. 


\section{Biografia}

Rudimar Gomes Bertotti

É Professor da rede municipal de ensino de Curitiba, é licenciado em História e Pedagogia. Mestre em Educação pela Universidade Federal do Paraná (UFPR) e Doutorando em Educação pela Pontifícia Universidade Católica do Paraná (PUC-PR). Grupo de Pesquisa: Grupo História das Instituições Escolares no Brasil (GIEB).

E-mail: rudigbertotti@gmail.com / ORCID: https://orcid.org/0000-0002-41347647

Rosa Lydia Teixeira Corrêa

É Professora do Programa de Pós-Graduação, Mestrado e Doutorado em Educação da Pontifícia Universidade Católica do Paraná (PUC-PR), é graduada em Pedagogia (UFPA). Mestrado em Educação (UNICAMP). Doutorado em História Econômica (USP). Grupo de Pesquisa: Grupo História das Instituições Escolares no Brasil (GIEB).

E-mail: rosa.correa@pucpr.br / ORCID: https://orcid.org/0000-0002-6416-4990 